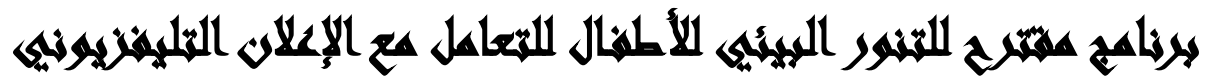

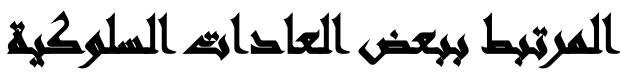

\section{[1 $\leqslant]$}

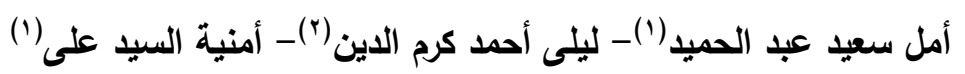

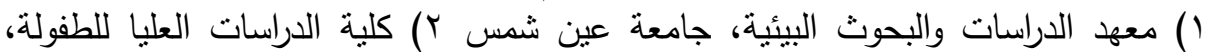

جامعة عين شمس الاتس

\section{المستخلم}

وهدفت الدراسة الحالية الي تحديد مستوي التتور البيئي لدي الأطفال قبل عمل برنامج

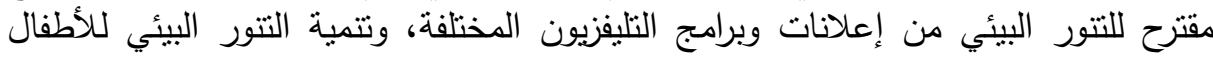

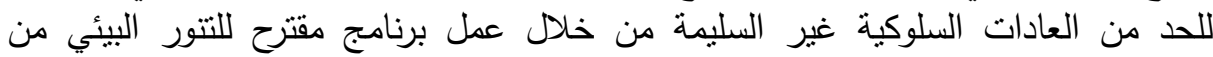

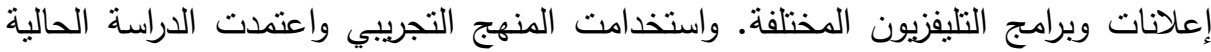

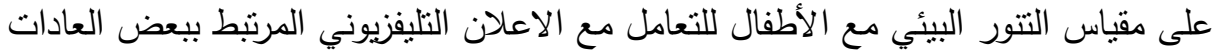

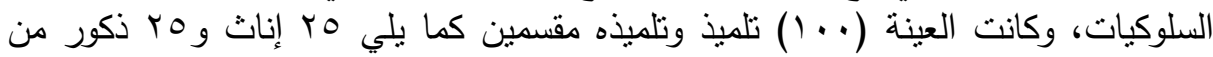

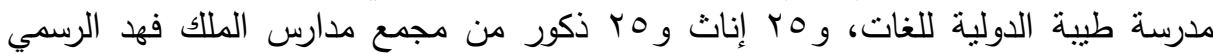

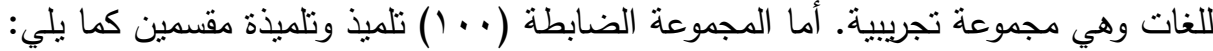

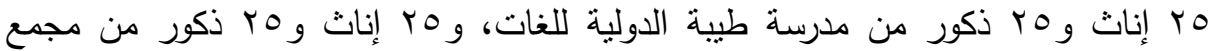

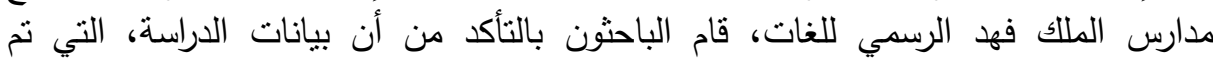

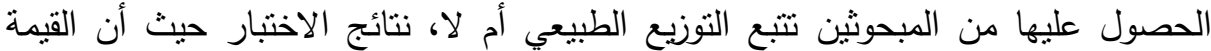

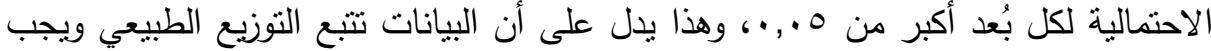

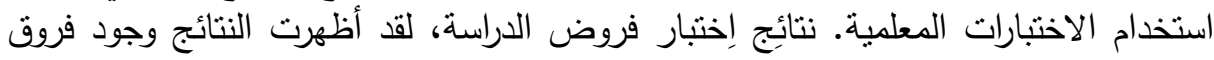

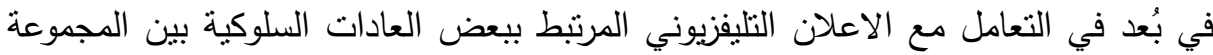

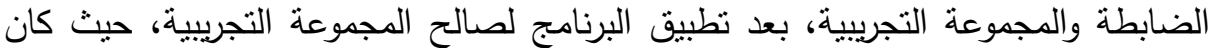

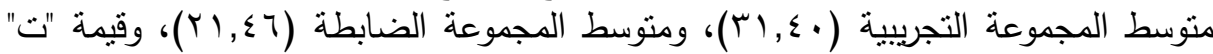

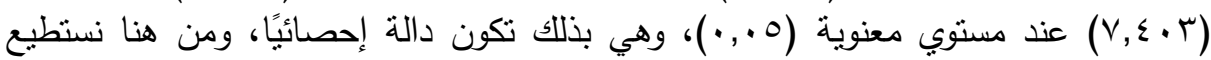

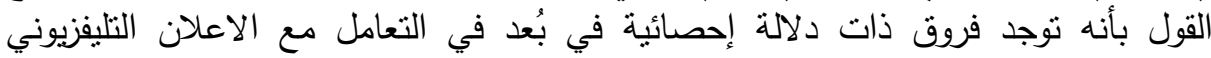

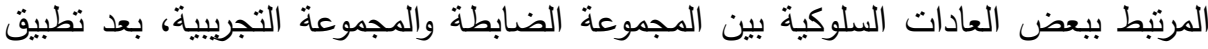

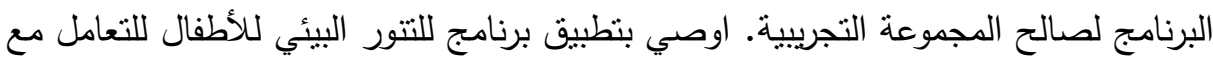

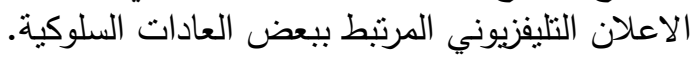




\section{$\sin$}

قد نزايد في العصر الحديث دور وسائل الإعلام تزايدًا كبيرًا وأصبح لأنواعها المتعددة دور واضحٌ وملموسُ وتأثيرُ في حياة الأفراد من خلال تتمية مستوى الوعي لديهم وزيادة

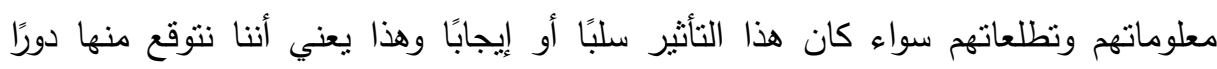

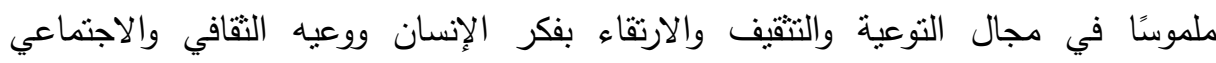
والصحي. ويقوم الاعلام دوراً مهماً في حياة الأمم والثعوب، ولا تكاد تخلو أمة من الأمم أو الأو

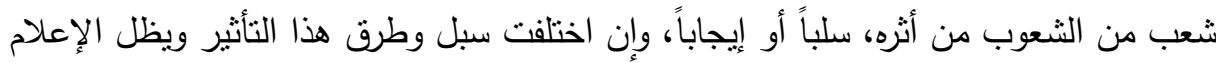

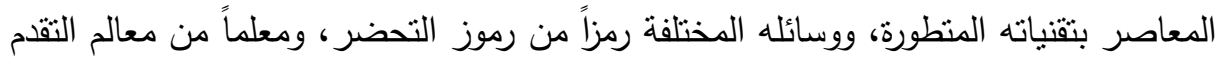

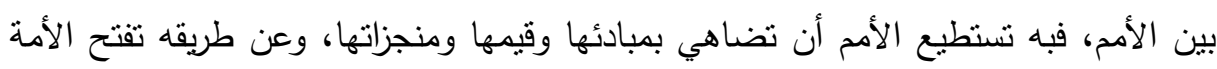

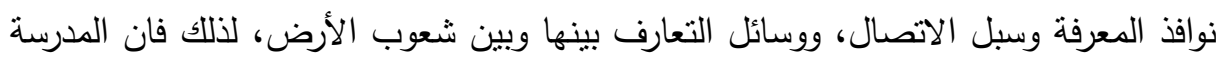

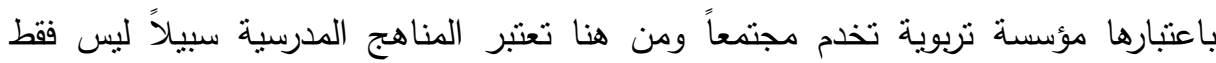
لاكتساب عناصر التتور البيئي لاي المتعلم في ضوء المراحل التي مرت بها فكرة التتوير

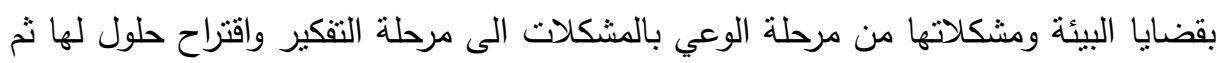
مرحلة التتفيذ الفعلي أو ما يسمي بالوظيفية وهذا يكفل للمتعلم السيل للمشاركة في مشكلات

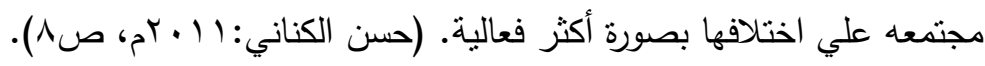

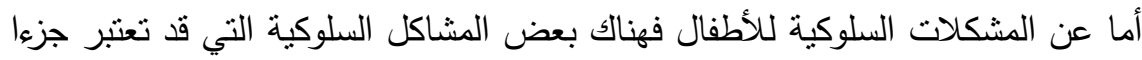

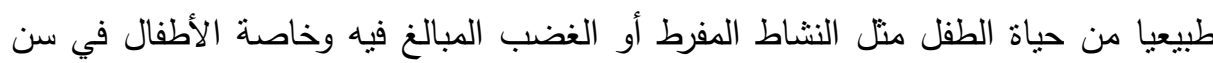

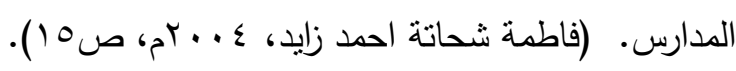

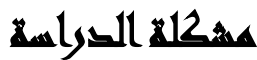

تُعد مرحلة الطفولة التي نبدأ من الميلاد إلى البلوغ، أهم المراحل العمرية على الإطلاق

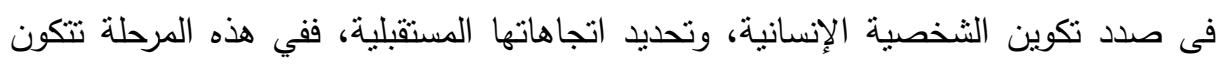
وتتبلور وتتفاعل العوامل المساهمة في توجيه مسار نمو وتطور شخصية الطفل، وهو الأمر

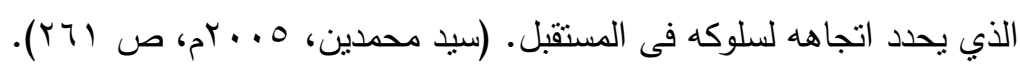


كما يوضع في مرحلة الطفولة أساس بناء شخصية الفرد ديناميكيا ووظيفياً ويوضع أساس السلوك المكتسب الذي يساعد الفرد في توافقه بمراحل النمو وفى مرحلة الطفولة يكون

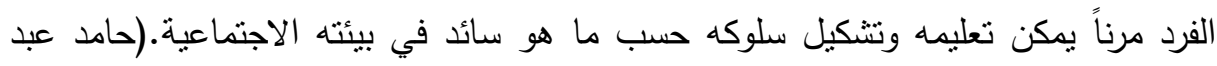

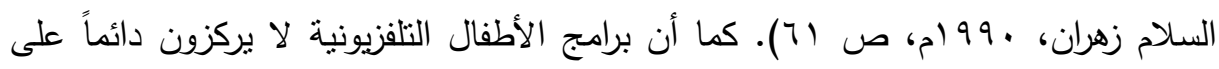

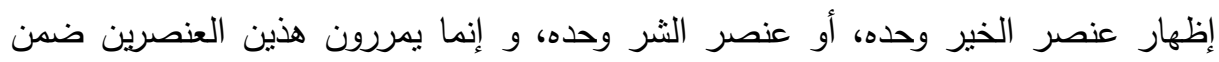

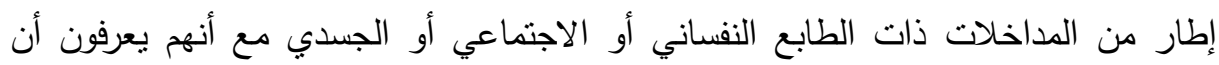

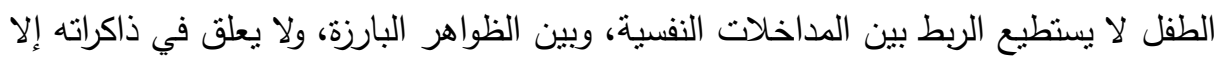

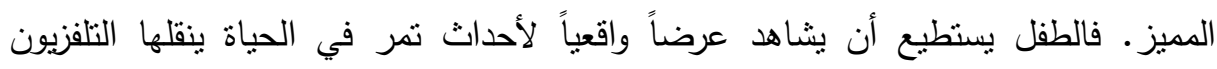

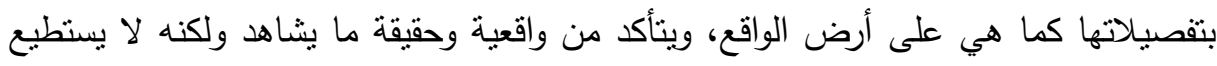

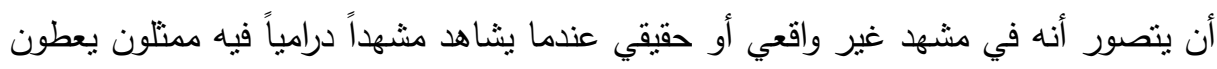
التنثيل حقه من تقصص الواقع بتفصيلاته. وقد اظهرت الدراسة الاستطلاعية النتائج الآتية ان اكثر من (V0\%) من افراد العينة

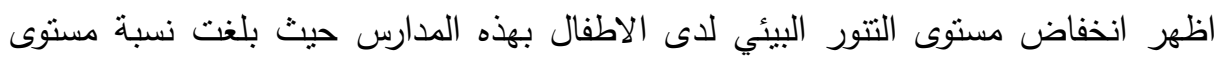
التتور البيئي عند عينة الأطفال (بدرسة صقر قريش التجريبية لغات) التي تم تطبيق الدراسة

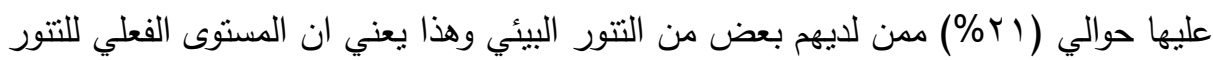

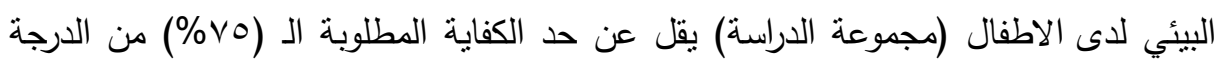
الكلية لمقياس التتور البيئي. تدور مشكلة الدراسة حول تدني مستوى التتور البيئي للأطفال،

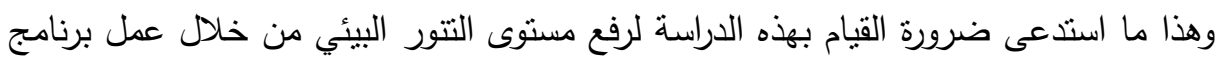

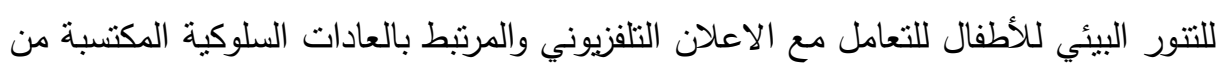

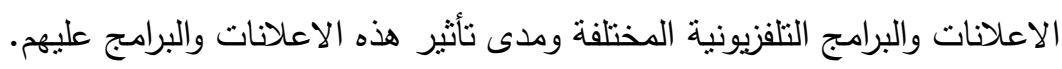

\section{أسميللة السواسمة}

(1) ما العادات السلوكية المرتبطة بالبيئة التي ينم تقديمها من خلال برنامج التتور البيئي

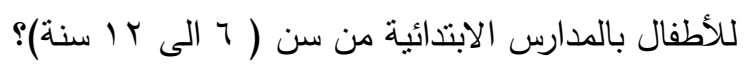

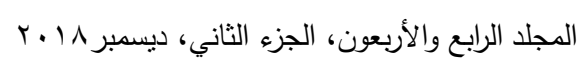


(r) ما شكل ومضمون البرنامج المقترح للتتور البيئي للأطفال في التعامل مع الاعلان

$$
\text { التليفزيوني المرتبط بالعادات السلوكية؟ }
$$

(ץ) ما مدى فاعلية هذا البرنامج المقترح للتتور البيئي والعادات السلوكية المرتبطة بالإعلانات

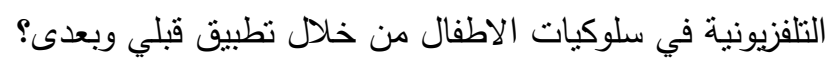

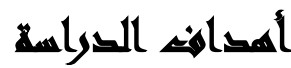

استهرفت الاراسة الحالية ما يلي:

1- تحديد مستوي التتور البيئي لدي الأطفال قبل عمل برنامج مقترح للتنور البيئي من اعندان إعلانات وبرامج التليفزيون المختلفة.

r- تتمية التتور البيئي للأطفال للحد من العادات السلوكية غير السليمة من خلال عمل برنامج مقترح للتتور البيئي من إعلانات وبرامج التليفزيون المختلفة. r- تحديد أثر اختلاف الجنس ( ذكور - إناث) علي مستوي التتور البيئي لدي الأطفال من خلال عمل برنامج مقترح للتتور البيئي من إعلانات وبرامج التليفزيون المختلفة.

\section{هغوضى التواسمة}

(1) توجد فروق ذات دلالة إحصائية بين المجموعة الضابطة والمجموعة التجريبية في بُعد التعامل مع الاعلان التليفزيوني المرتبط ببعض العادات السلوكية لصالح المجموعة لهند

$$
\text { التجريبية. }
$$

(r) توجد فروق ذات دلالة إحصائية بين المجموعة الضابطة والمجموعة التجريبية في بُعد التأثر السلبي للإعلان التليفزيوني والتعامل معها لصالح المجموعة التجريبية. (T) توجد فروق ذات دلالة إحصائية بين المجموعة الضابطة والمجموعة التجريبية في بُعد ولئي السلوكيات المكتسبة من الإعلان التلافزيوني لصالح المجموعة التجريبية.

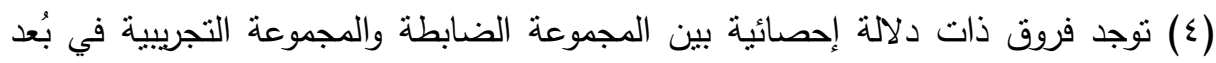

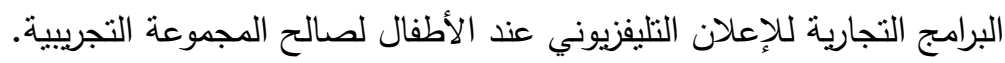

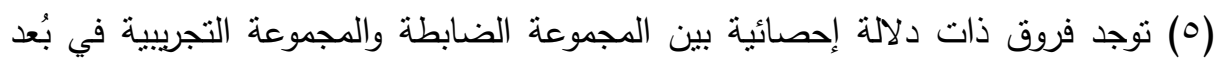
النتوير التعليمية للإعلان التليفزيوني عند الأطفال لصالح المجموعة التجريبية. 
(7) نوجد فروق ذات دلالة إحصائية بين المجموعة الضابطة والمجموعة التجريية في إجمالي

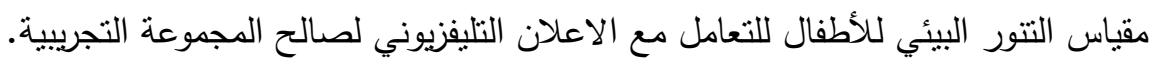

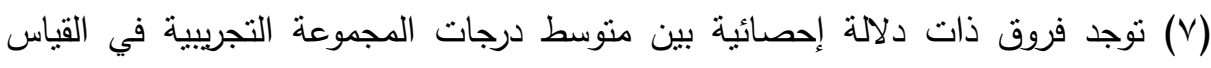

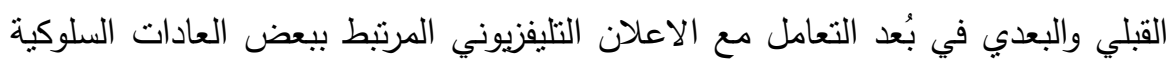
لصالح القياس البعدي.

(^) توجد فروق ذات دلالة إحصائية بين متوسط درجات المجموعة التجريبية في القياس

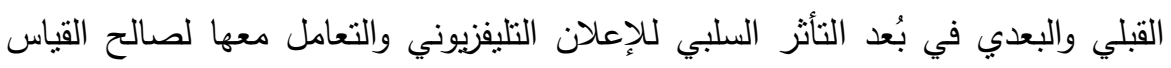
البعدي.

(9) توجد فروق ذات دلالة إحصائية بين منوسط درجات المجموعة التجريبية في القياس

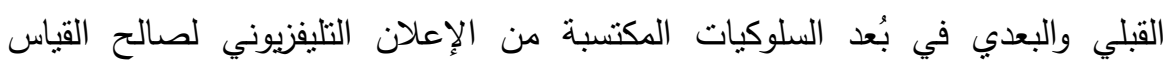
البعدي. ( • (1) توجد فروق ذات دلالة إحصائية بين متوسط درجات المجموعة التجريبية في القياس

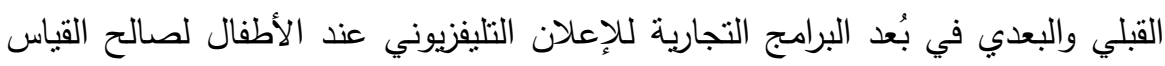
البعدي.

\section{م=وض القواسمة}

الحدود الزمنية: تمثل في تطبيق الجزء العملي الخاص بالدراسة. الحدود المكانية: إجراء التطبيق للدراسة في مدرسة صقر قريش التجريبية لغات مشتركة بالقاهرة. الحدود البشرية: ينت التطبيق على مجموعة من الاطفال (؟ب) طفل في المرحلة الابتدائية

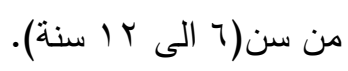




\section{هنهمج التواسلة}

اعتمدت الدراسة على المنهج شبة التجريبي: من خلال استخدام التصميم للمجموعة

التجريبية الواحدة (القبلي- والبعدي) للتعرف على أثز متغير مستقل على متغير نابع حيث يتم دراسة أثر المتغير المسنقل (برنامج مقترح للتتور البيئي) على متغير تابع باستخدام المتغير التابع (الأطفال) للتعامل مع الاعلان التلفزيوني وتعديل بعض العادات السلوكية.

\section{أهمي التصواسم}

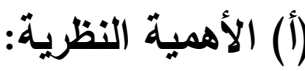

1- تسهم الدراسة علي تقديم مقياس لمعرفة التتور البيئي للأطفال من خلال تعاملهم مع الإهي الإعلانات التلفزيونية المرتبطة بالعادات السلوكية.

r- إثارة إلي ما أكدته بعض الدراسات العربية من اعتماد نسبة كبيرة في الإعلانات بات باتهاته التلفزيونية علي شخصيات أجنبية فإن دراسة صور الأطفال الإعلانية من ناحية التعرف إنساته

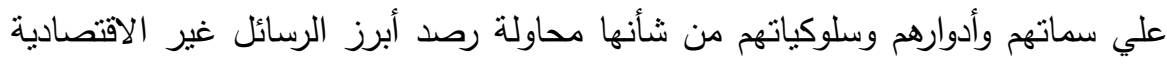
التي أريد إيصالها إلي الطفل المتلقي، وتمثل أهمية خاصة عند دند دراسة ملادمح التأثنرات الاجتماعية والتربوية والثقافية للإعلان التلفزيوني علي الأطفال تحديداً.

\section{(ب) الأهمية التطبيقية:}

1- جاءت اهمية الدراسة التطبيقية من مضمون إعلانات القنوات للأطفال له جاذبية خاصة

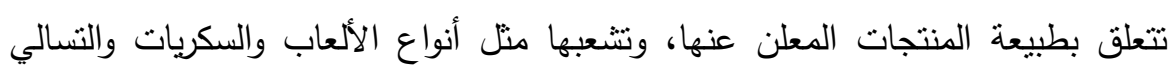
وبعض الأغذية المحفوظة، في مقابل غياب إعلانات منتجات أخرى نظهر في القنوات

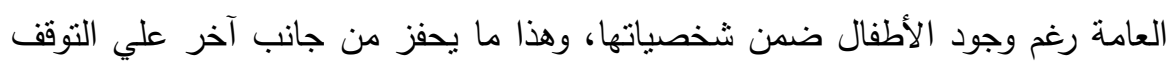
عند تأثير التعاملات التسويقية علي ضوء تركيز هذه القنوات علي إعلانات منتجات معينة قد لا يكون في تكثيفها مردود إيجابي للطفل المشاهد.

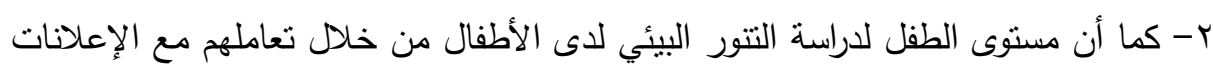

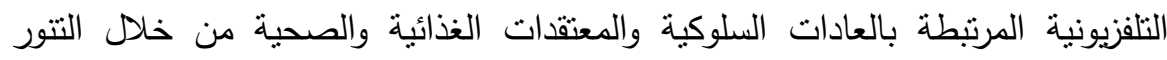


البيئي، وكذللك تعويد الأطفال على إنباع أفضل الطرق لاستغلال ما يتوفر لديهم من

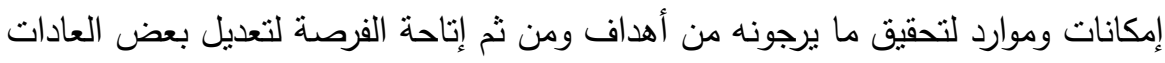
السلوكية الخاطئة.

\section{مسطلحاهي التوراسم}

استعانت الباحثة بعدد من المصطلحات هي:

1- مفهوم التنور البيئي: (Environmental Literacy): التتور البيئي في جوهره

القدرة علي تفسير عمل النظم البيئية واتخاذ التدابير الملائمة لسلامتها وتحسين عملها

ومسئولية الإنسان عن حمايتها البيئة وصيانتها. (السيد محمد السايح، ع 99 (م).

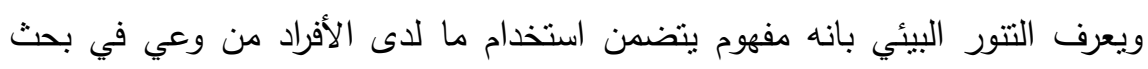

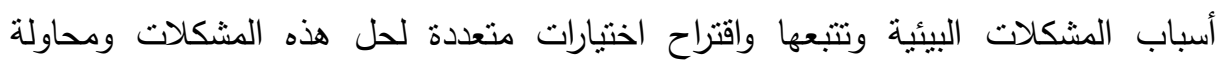

إخضاعها للتجريب والاختبار ومشاركة المعلم والمتعلم في إيجاد حلول للمشكلات البيئية.

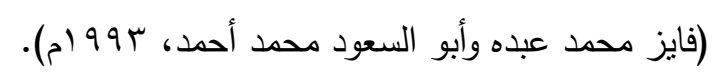

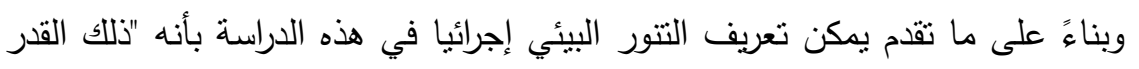

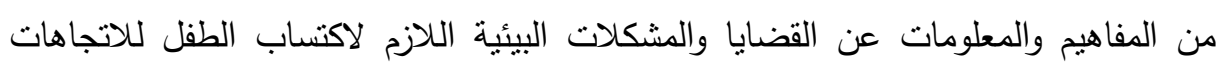

الإيجابية نحو دراسة البيئة والتفاعل معها.

r - تعريف الاعلان التلفزيوني (television advertising): الإعلان التلفزيوني

"TV Advertisement" هو مجموعة من الوسائل الفنية المتتوعة المستخدمة من خلال

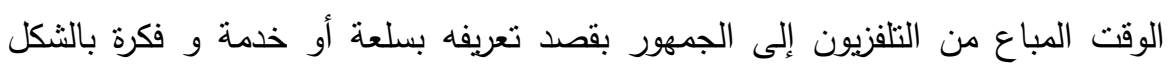
المضمون الذي يؤثز في معلوماته و ميوله و قيمه و سلوكه الاستهلاكي و أمثاله وسائل

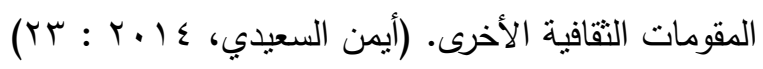

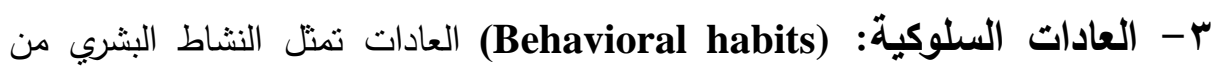
طقوس أو تقاليد نستمد في أغلب الأحيان من فكر أو عقبدة الختمع وتدخل العادات في كثثر من مناحي الحياة.

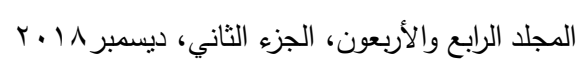




\section{الصوراسايت الماريهة}

1- دراسة (أماني محمد ץ . . rم). وقد استهرفت الدراسة إلي تثخيص وتعديل

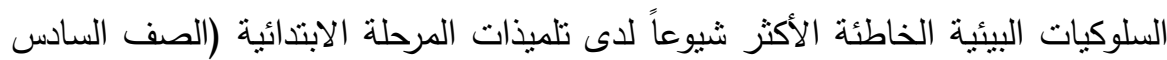

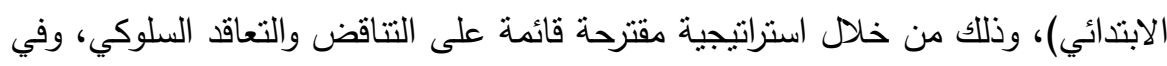
ضوء هذا الهلف سعت الدراسة للإجابة عن الأسئلة التالية ما السلوكيات البيئية الخاطئة البأية

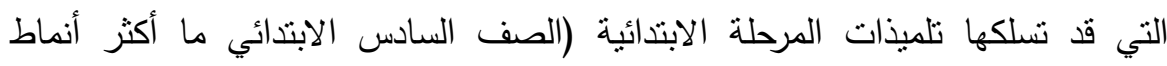

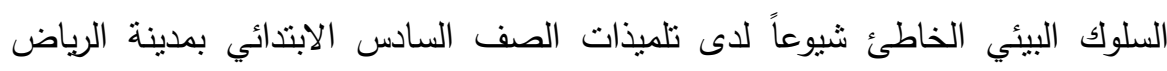
ومدى وعي هولّاء التلميذات بالخطأ في تلك الأنماط.

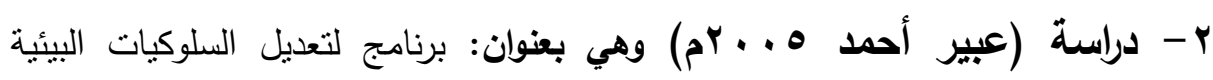

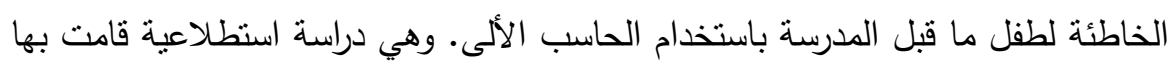

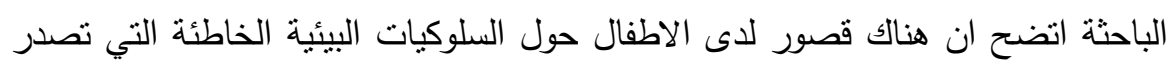

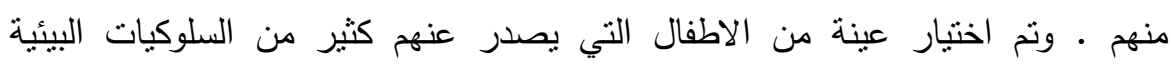
الخاطئة وتم تطبيق اداة البحث على افراد العينة كما تم تطبيق بطاقة الملاحظة من قبل العان

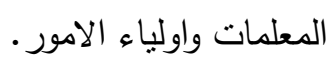

r- دراسة (سكينة إبراهيم ؟ + . rم) وهدفت هذه الدراسة الى فاعلية استخدام الانثطة

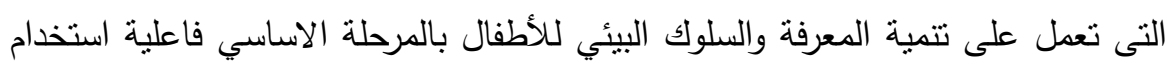

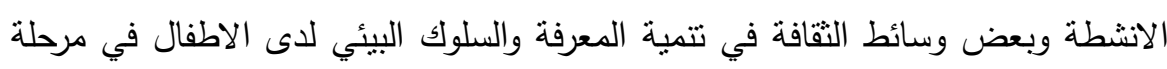

$$
\text { التعليم الأساسي بلييا. }
$$

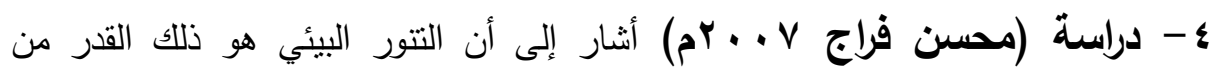

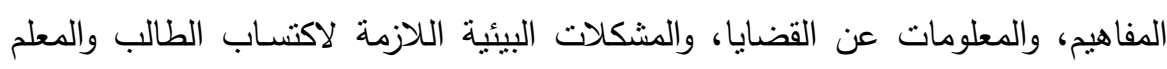

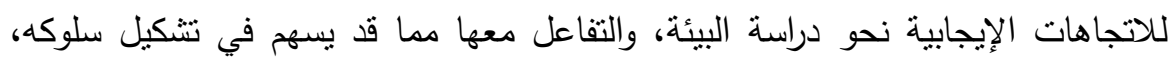

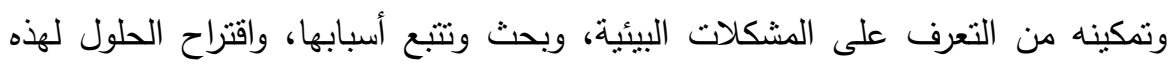

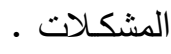




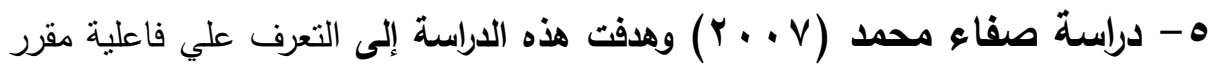
الإكتروني في تتمية التتور البيئي والتفكير المنظومى وذلك بالنسية إلى بعض طلاب كليه التربية بالوادي الجديد. وتوصلت الدراسة الى فاعلية مقرر الكترونى في تتمية التتور البيئي والتفكير المنظومى ومهارات التواصل الإلكتروني لدى بعض طلاب كليه التربية بالوادي

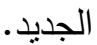

צalaardingerbroek \& Taylor, 2007) - دراسة فلا رد ينجر بروك وتايلور ) بدراسة مقارنة (A Comparative Study) هدفت الكثف عن الثقافة البيئية والاتجاهات نحو البيئة لدى الطلبة المعلمين في لبنان مقارنة مع عينة مكافئة من طلبة

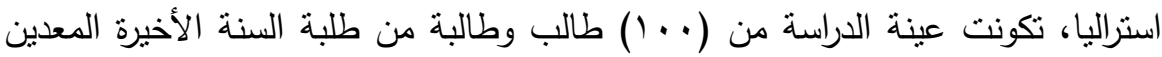
لتدريس الصفوف الأساسية والثانوية في الجامعة الأمريكية في بيروت والجامعة الأمريكية

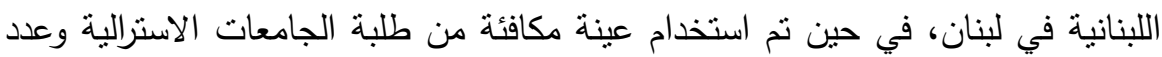

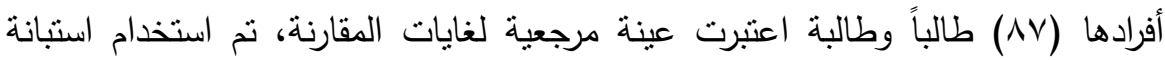
بغرض جمع بيانات الدراسة. أظهرت نتائج الدراسة أن الطلبة اللبنانيين يتخلفون وراء لهاء أقرانهم في استراليا فيما يتعلق بإدراكهم للقضايا البيئية العالمية. V- دراسة (حازم أحمد ^ . . r م) وهدفت هذه الدراسة الى معرفة أثز برنامج بالوسائط المتعددة على تعزيز قيم الانتماء الوطني والوعي البيئي لدي طلاب الصف التاسع في محافظات غزة وذللك عن طريق الاجابة عن الاسئلة التالية ما أثز برنامج بالوسائط

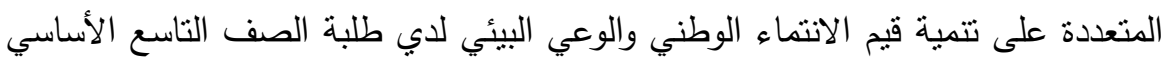

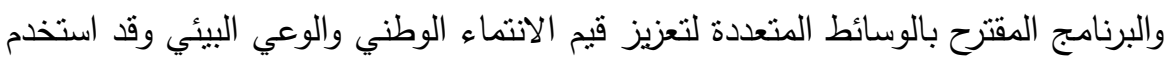

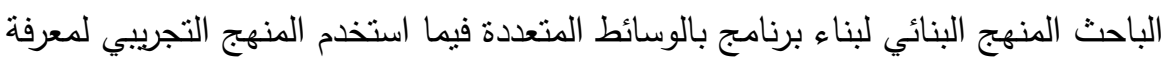
تأثثر البرنامج علي عينة مكونة من •0 طالب نم تقسيمها إلي مجموعة تجريبية وأخري ضابطة وتوصلت الدراسة إلي أهم النتائج ومنها توجد فروق ذاته دات دلالة احصائية عند

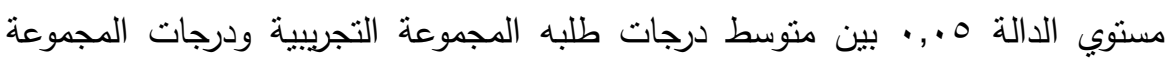
الضابطة في اختبار الوعي البيئي، يعزي البرنامج المقترح. وكذلك في الانتماء الوطني.

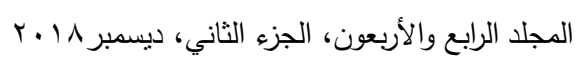




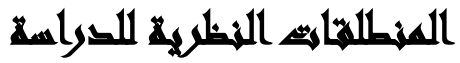

نظرية التعلم الإجرائي:

نظرية التعلم الإجرائي: هي نتاج نسق من الأبحاث في مجال علم النفس يعرف باسم

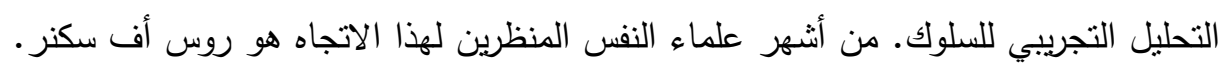

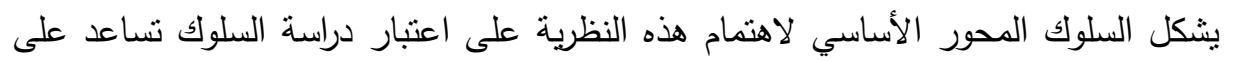

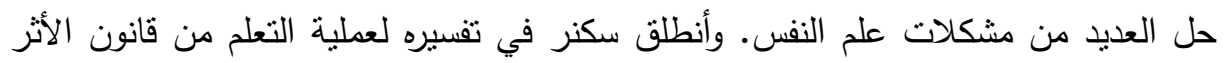

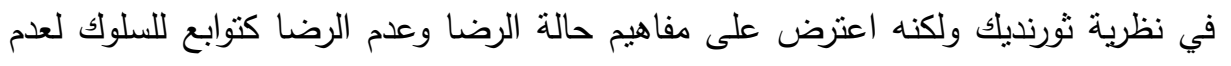

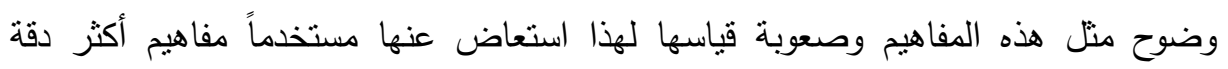
ووضوحاً تتمثل في التعزيز والعقاب. وقد ميز سكنر بين نوعين من التعلم وفقاً لنوع السلوك وهئ الذي يصدر وهما: أولاً: التعلم الاستجابي: هي مجرد منعكسات لا إرادية تحدث تأثيراً أو تغييراً في البيئة، في استجابات طبيعية (منعكس طبيعي) لمثير طبيعي مثل هذه الاستجابة طبيعية غير متعلمة في

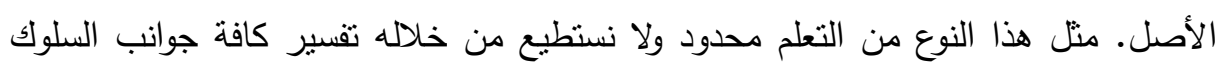

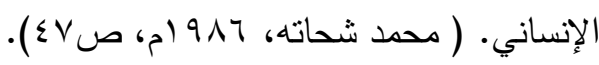

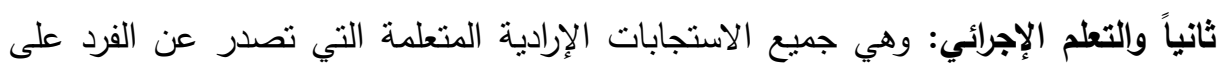

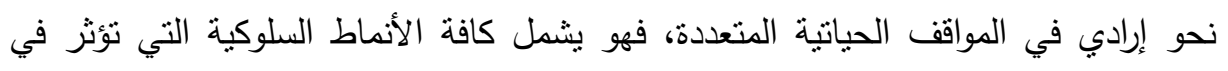
البيئة وتحدث تغييراً فيها وتسمى مثل هذه السلوكيات بالسلوكيات الغرضية أو الوظيفية.

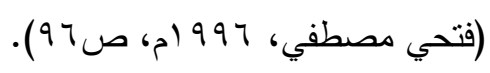

توابع السلوك: إن عملية الاحتفاظ بسلوك معين وتكراره تتوقف على النتائج المترتبة عليه وهي

$$
\begin{aligned}
& \text { ما تعرف بالمثيرات البعدية، وهي على فئتين: } \\
& \text { • المثيرات العقابية الاجتماعية. }
\end{aligned}
$$

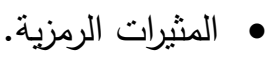

هذا وتتمثل المعاقبات الداخلية المصدر في الثعور بالألم والندم. 
وينظر إلى الانسان في هذا الاتجاه على أنه عضوية بيولوجية يجب أن تتفاعل مع البيئة

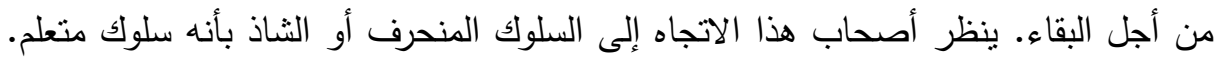

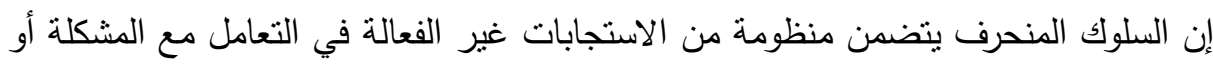
التي لها تأثثرات جانبية غير مرغوب فئها.

\section{إجبراعاهـ القواسمة}

أولا: منهج الدراسة: اعتدت الدراسة الحالية استخدام الدنهج التجريبي • ثانيا: مجتمع الدراسة: يشتمل على أطفال الصف الرابع والخامس والسادس من مدرستي طيبة الدولية للغات والملك فهد الرسمي للغات. وقد تألفت عينة الدراسة من:

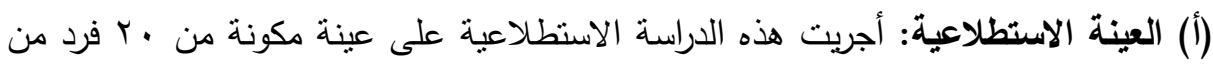
أجل الإجابة على • 7 مفردة، للتأكد من صدق وثنبات الاسنط الاختبار المقياس. (ب) أداة القياس: اعتمدنا في دراستتا الحالية على اختبار من أعداد الباحثون لقياس التتور

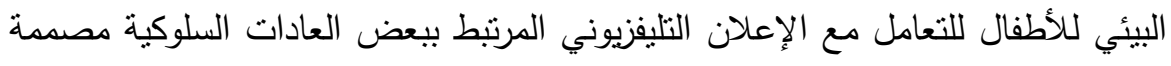
من قبل الباحثون وذللك من أجل جمع البيانات الخاصة بموضوع الدراسة. ويتكون هذا المقياس من جزئيين، الجزء الأول يتضمن المعلومات الثخصية، والجزء الثاني يتضمن الثنان العبارات الخاصة لقياس التتور البيئي للأطفال.

(ج) عينة الاراسة: وتتقسم إلى المجموعة التجريبية: ( · ( ) تلميذ وتلميذة مقسمين كما يلي:

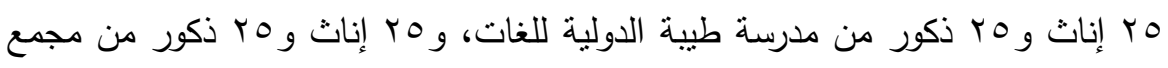

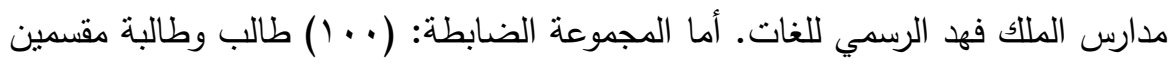

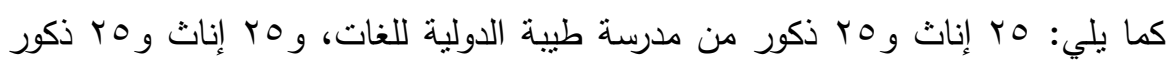
من مجمع مدارس الملك فهد الرسمي للغات. وتكون مقياس الدراسة من الجزء الأول:

$$
\text { ويشمل (البيانات الاساسية). }
$$


أما الجزء الثاني: ويشمل العبارات الخاصة ببرنامج التتور البيئي للأطفال ويبلغ عدد عباراته

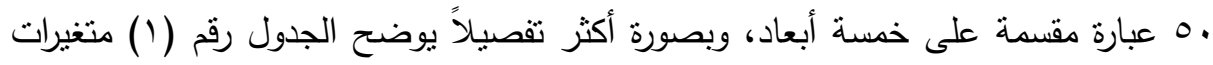

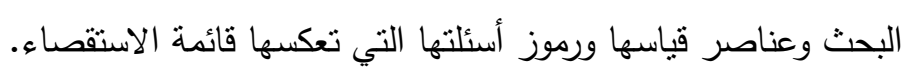
جدول رقم( ) : يوضح متغيرات البحث وعناصر قياسها ورموز أسئلتها

\begin{tabular}{|c|c|c|c|}
\hline حدود الاسئلة & 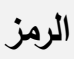 & 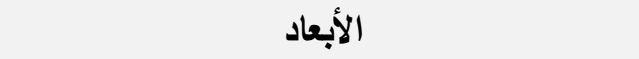 & 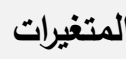 \\
\hline $1-11$ & $\mathrm{X} 1$ & التعامل مع الاعلادات التليفزيوني المرنبط ببعضي & \multirow{5}{*}{ لبرأبنامج } \\
\hline $12-21$ & $\mathrm{X} 2$ & التأثر السلبى للإعلان التليفزيونى والتعامل معها & \\
\hline $22-30$ & $\mathrm{X} 3$ & السلوكيات المكتسبة من الإعلان التلبفزيوني & \\
\hline $31-39$ & $\mathrm{X} 4$ & البرامج التجارية للإعلان التنليفزيونى عند الأطفال & \\
\hline $40-50$ & $\times 5$ & التتوير التعليمية للإعلان التليفزيونى عند الأطفال & \\
\hline
\end{tabular}

وقد نم قياس استجابات أفراد العينة لفقرات المقياس، طبقا لمقياس ليكرت الخماسي. ومن خلال ذللك إعداد برنامج لتتمية عناصر التنور البيئي للإجابة عن السؤال البيئي حيث نم إعداد البرنامج وفق الخطوات التالية:

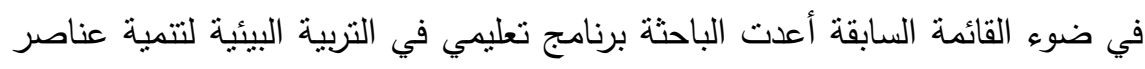
التتور البيئي (التعامل مع الاعلان التليفزيوني المرتبط ببعض العادات السلوكية، بعائية التأثر السلبي

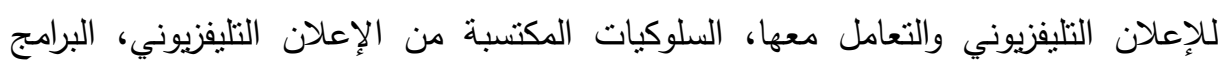

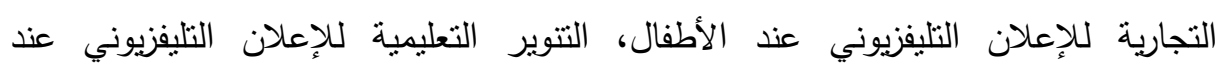
الأطفال) • وفيما يلي عناصر البرنامج المقترح:

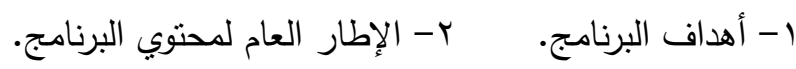

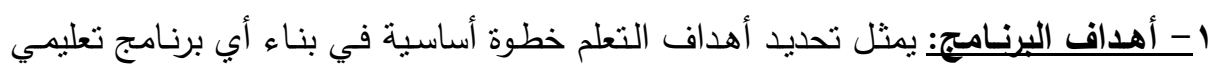
حيث أن المحتوي لتعليمي لأي برنامج ينوقف علي طبيعة الأهداف. ويري بعض مصمدي لئي البرامج التعليمية أن تحديد أهداف التعلم يجب أن تكون خطوة مبكرة في عملية البناء تأني

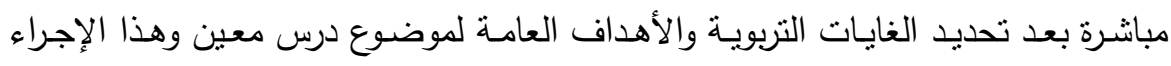
صحيح من حيث أسس التتظيم وتتابع محتوي وخبرات البرنامج التعليمي وذلك لأن تحديد الأهداف التعليمية هي أساس أب نشاط تعليمي هادف. 
ب - الاطار العام لمحتوي البرنامسج: ويحتوي علي ثلاثة عشر جلسـة وكل جلسـة ه ؛ دقيقة وقت انتهاء البرنامج ويعد الانتهاء من البرنامج لابد من معرفة الأهداف التالبة: • الأهداف المعرفية: بعد الإنتهاء من الموضوع ينبغى أن يكون الطفل قادر على أن: 1- تذكر أسباب المشكلة. - نسنتتج الأثار المنرتبة علي السلوكيات الخاطئة في البيئة.

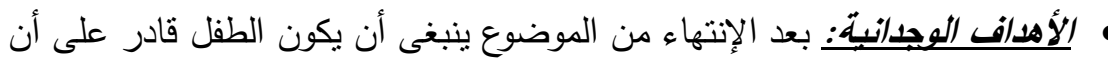

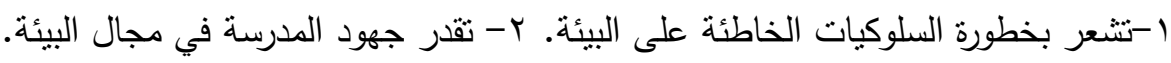

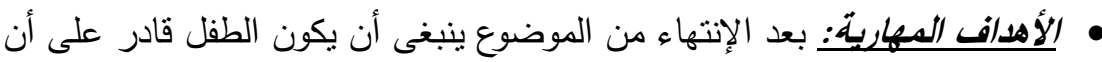
1- تعد تقارير عن الفئات العمرية في المدرسة. r- تخطط لزيارة المدرسة ونتظيم الندوات البيئية. r- تقترح بعض الحلول للمشكلة. صدق وثبات أداة الاراسة: ويشمل وصف أداة الدراسة علي صدق الاتساق الظاهري وثبات وصدق الاتساق الداخلي لأداة الدراسة وذلك على ولثئ النحو التالي: أولا: الصدق التمبيزي: نعني به قدرة الاختبار على التمييز بين الهجموعات الدختلفة، أو حتى لادى الأفراد التي تقع درجاتهم على طرفي المنحنى.

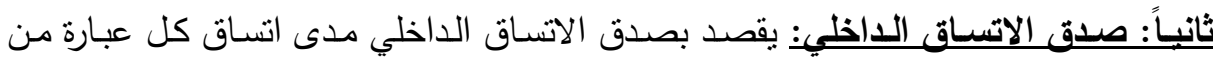
عبارات الاستبيان مع البعد الذي تتنمي إلية هذه العبارة، وقد قامت الباحثة بحساب الاتساق

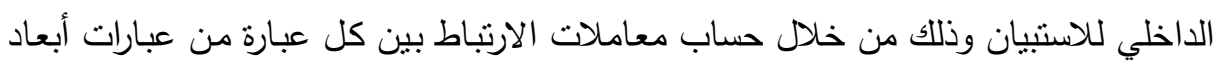
الاستنيان والدرجة الكلية للبعد نفسه. ثالثاً: الصدق البنائي: هو أحد مقاييس صدق الأداة الذي يقيس مدى تحقق الأهداف التي تريد الأداة الوصول إليها، وبيين مدي ارتباط كل بعد من أبعاد الدراسة بالدرجة الكلية لعبارات الإنيات لايعاً: الثبات: يقصد بثبات أن يعطي هذه المقياس نفس النتيجة لو تم إعادة توزيعه أكثر من مرة تحت نفس الظروف والثروط. قد قامت الباحثة من التحقق من صدق الاتساق الداخلي والصدق البنائي وثبات الاستبيان من خلال تطبيقه على عينة استطلاعية مكونة ( • آ) فرد.

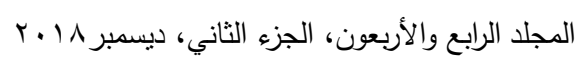


نتائج الصدق التمييزي: لسحاب القوة التمييزية رتبت الدرجات الكلية التي حصل عليها من

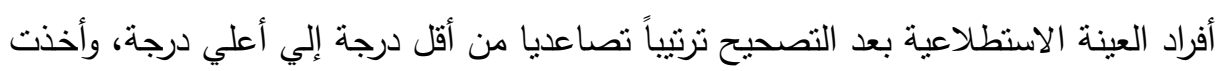

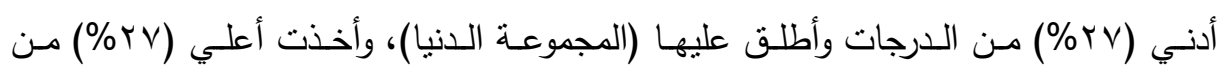

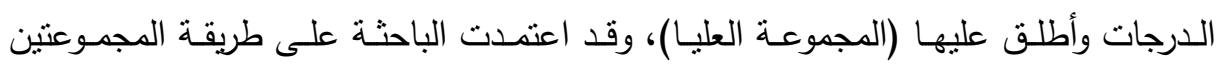
المتطرفنتين، والجدول رقم (Y) يوضح نتائج هذا الإجراء.

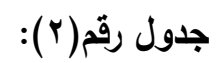

\begin{tabular}{|c|c|c|c|c|c|c|c|}
\hline الاستدلال & دلالة مستوي & قيمة & الحرية & الاععياري & المتوسط & العدد & المستويات \\
\hline \multirow[t]{2}{*}{ دالة } & \multirow{2}{*}{0.00} & \multirow{2}{*}{-9.002} & \multirow{2}{*}{30} & 1.11385 & 6.0012 & 16 & $\begin{array}{c}\text { المجوعة الد r } \\
\text { \% }\end{array}$ \\
\hline & & & & 0.25192 & 8.5713 & 16 & 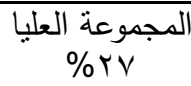 \\
\hline
\end{tabular}

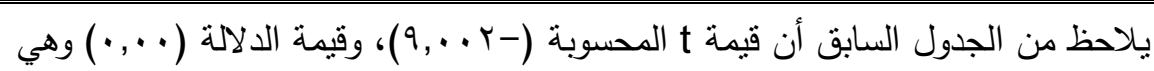

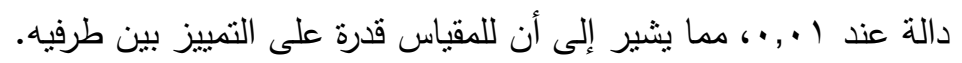

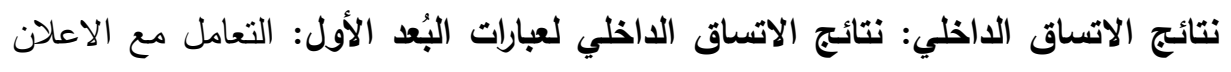

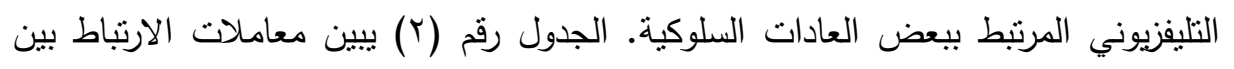

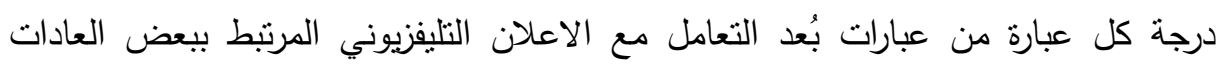
السلوكية مع الدرجة الكلية لذلك البُعد، مع بيان مستوى الدلالة الإحصائي.

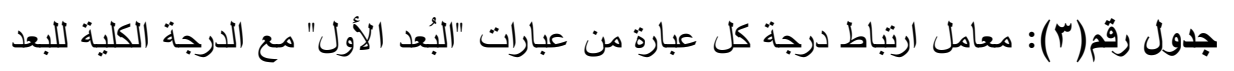

$$
\text { 7. }=\text { ن }
$$

\begin{tabular}{|c|c|c|c|c|c|}
\hline مستوي الدلالة & معامل الارتباط & العبارة & الدلائة & معامل الارتباط & رالعبارة \\
\hline 0.000 & $0.542(* *)$ & 7 & 0.000 & $0.911(* *)$ & 1 \\
\hline 0.000 & $0.654(* *)$ & 8 & 0.000 & $0.808(* *)$ & 2 \\
\hline 0.000 & $0.917(* *)$ & 9 & 0.000 & $0.874(* *)$ & 3 \\
\hline 0.000 & 0.809 (**) $^{*}$ & 10 & 0.000 & $0.823(* *)$ & 4 \\
\hline 0.000 & $0.857(* *)$ & 11 & 0.000 & 0.679 (**) & 5 \\
\hline & & & 0.000 & $0.832(* *)$ & 6 \\
\hline
\end{tabular}


يتضح من الجدول السابق أن جميع عبارات بُعد التعامل مع الاعلان التليفزيوني المرتبط

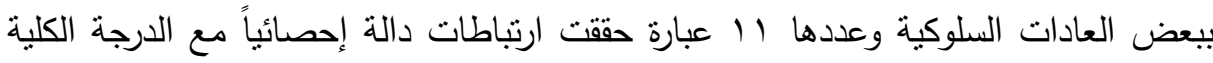
لذلك البعد، وبذلك يعتبر البعد صادق لما وضع لقياسه. نتائج ثبات المقياس: تحققت الباحثة من ثبات المقياس الدراسة من خلال طريقتين وهما طريقة التجزئة النصفية ومعامل ألفا كرو نباخ. أولاً: طريقة التجزئة النصفية: Split-Half Coefficient method بطريقة التجزئة النصفية، حيث احتسبت درجة النصف الأول لكل بعد من أبعاد المقياس وكذلك درجة النصف الثاني من الدرجات وذلك لحساب معامل الارتباط بين النصفين ثم جري لإنه

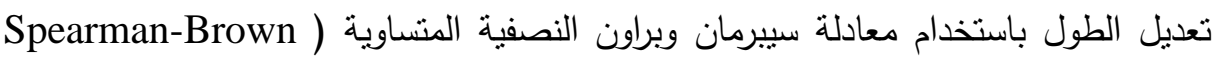

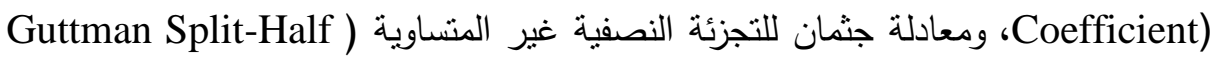
(Coefficient الجدول رقم(؛ ): يوضح معاملات الارتباط بين نصفي كل أبعاد المقياس قبل وبعد التعديل $1 \cdot=\dot{0}$

\begin{tabular}{|c|c|c|c|c|}
\hline التبات بعد & الارتباط & 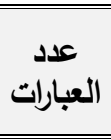 & الأبعاد & b \\
\hline 0.960 & 0.955 & 11 & التعامل مع الاعلان التليفزيونى المرنبط ببعض العادات & 1 \\
\hline 0.969 & 0.947 & 10 & التأثر السلبى للإعلان التليفزيونى والتعامل معها & $r$ \\
\hline 0.967 & 0.949 & 9 & السلوكيات المكتسبة من الإعلان التليفزيوني & r \\
\hline 0.924 & 0.912 & 9 & البرامج التجارية للإعلان التليفزيونى عند الأطفال & $\varepsilon$ \\
\hline 0.987 & 0.982 & 11 & التتوير التعليمية للإعلان التليفزيونى عند الأطفال & 0 \\
\hline 0.717 & 0.559 & 50 & إجمالى ابعاد المقياس & \\
\hline
\end{tabular}

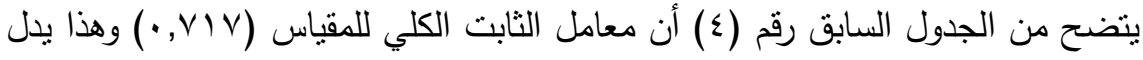
على أن ابعاد المقياس تتمتع بدرجة عالية جدا من الثبات تطمئن الباحثة إلى تطبيقها على

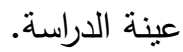


ثانيا: طريقة ألفا كرو نباخ: Alpha Cronbach: استخدمت الباحثة طريقة أخري من طرق حساب الثبات وهي طريقة ألفا كرو نباخ، وذللك بغرض التحقق من ثابت أداة الدراسة،

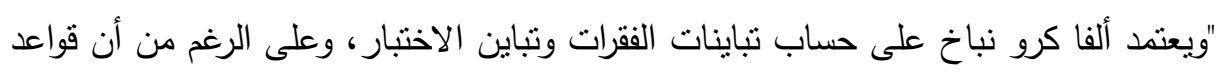

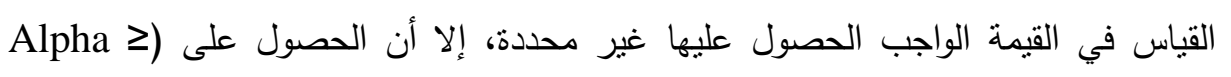
• الأساليب الإحصائية المستخدمة: لتحقيق أهداف الدراسة وتحليل البيانات التي نم تجمعها، فقد تم استخدام الأساليب الإحصائية المناسبة باستخدام برنامج الإحصائي لتحليل البيانات ومعالجاتها. فيما يلي مجموعة من الأساليب الإحصائية المستخدمة في تحليل البيانات: 1- تم ترميز وإدخال البيانات إلى الحاسب الآلي، حسب مقياس ليكرت الخماسي (1 غير

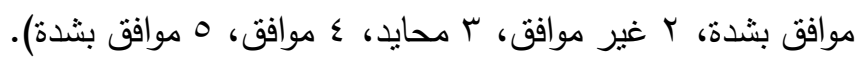

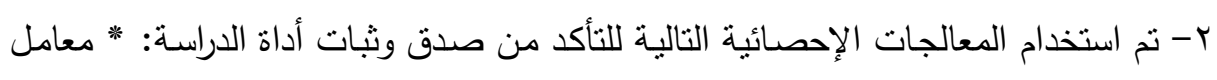

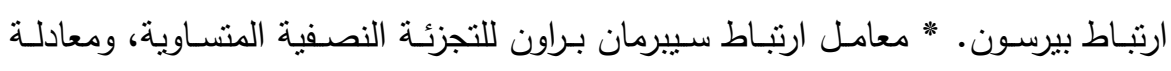

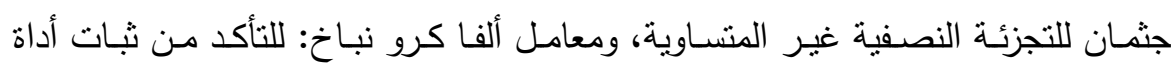
الدراسة.

r- اختبار كولومجروف- سمير نوف لمعرفة نوع البيانات، هل تتبع التوزيع الطبيعي أم لا. ع - نم استخدام المعالجات الإحصائية التالية لتحليل نتائج الدراسة الميدانية.

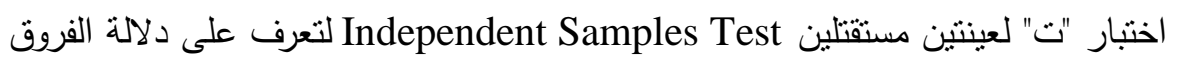
بين المجموعة الضابطة والمجموعة التجريبية. اختبار "ت" لعينتين مرتبطتين Paired Samples Test لتعرف على دلالة الفروق بين الاختبار القبلي والبعدي للمجموعة التجريبية.

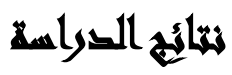

أهم نتائج الاراسة الحالية ومنها: توجد فروق ذات دلالة إحصائية بين المجموعة الضابطة والمجموعة التجريبية في بُعد التعامل مع الاعلان التليفزيوني المرتبط ببعض العادات 380

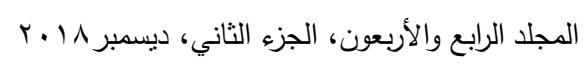


السلوكية لصالح المجموعة التجريبية. للتحقق من صحة هذا الفرض قامت الباحثة باستخدام

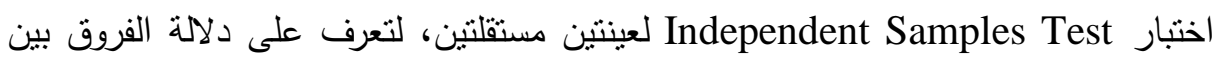
المجموعة الضابطة والمجموعة التجريبية. جدول رقم(ه): يوضح الفروق بين المجموعة التجريبية والمجموعة الضابطة في بُعد التعامل مع الاعلان التلبفزيوني المرتبط ببعض العادات السلوكية بعد تطبيق البرنامج

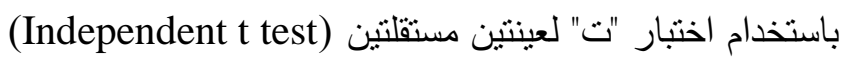

\begin{tabular}{|c|c|c|c|c|c|c|c|}
\hline \multirow{2}{*}{ النتيجة } & \multirow{2}{*}{ مستوي } & \multirow{2}{*}{ 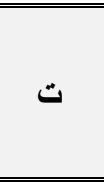 } & \multicolumn{2}{|c|}{ الضابطوعة } & \multicolumn{2}{|c|}{ المجموعة التجريبية } & \multirow{2}{*}{ المقياس } \\
\hline & & & انحرافي & متوسط & معياري & متوسي & \\
\hline دالة & 0.00 & 7.403 & 5.772 & 21.46 & 12.138 & 31.40 & بُبعد التليفزيوني المعرتبط الاعلان \\
\hline
\end{tabular}

من الجدول السابق رقم (0) يتضح ما يلي: لقد أظهرت النتائج وجود فروق في بُعد في التعامل مع الاعلان التليفزيوني المرنبط ببعض العادات السلوكية بين المجموعة الضابطة

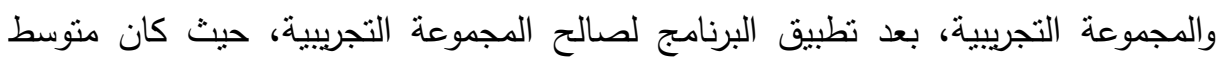

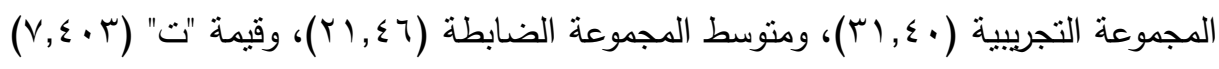
عند مستوي معنوية (0., ).)، وهي بذلك تكون دالة إحصائيًا، ومن هنا نسنطيع القول بأنه

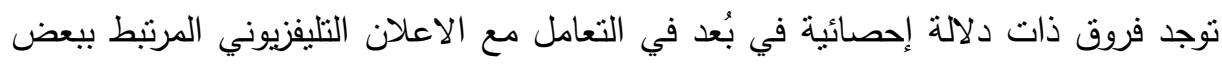

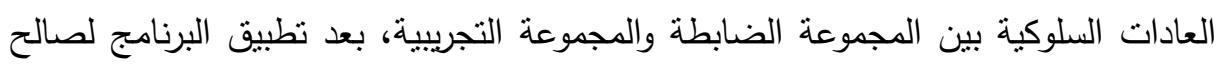
المجموعة التجريبية. لا توجد فروق ذات دلالة إحصائية بين المجموعة الضابطة والمجموعة التجريبية في بُعد التأثر السلبي للإعلان التلبفزيوني والتعامل معها لصالح المجموعة التجريبية. Independent للتحقق من صحة هذا الفرض قامت الباحثة باستخدام اختبار Samples Test والمجموعة التجريبية. 
جدول رقم(؟): يوضح الفروق بين المجموعة التجريبية والمجموعة الضابطة في بُعد التأثز السلبي للإعلان التليفزيوني والتعامل معها بعد تطبيق البرنامج باستخدام

اختبار "ت" لعينتين مستقلتين (Independent t test)

\begin{tabular}{|c|c|c|c|c|c|c|c|}
\hline \multirow[b]{2}{*}{ التيجة } & \multirow{2}{*}{ مستوي الالالة } & \multirow[b]{2}{*}{$ت$} & \multicolumn{2}{|c|}{ المجموعة الضابطة } & \multicolumn{2}{|c|}{ المجموعة التجريبية } & \multirow[b]{2}{*}{ المقياس } \\
\hline & & & معياري & متابي & معياري & متوبط & \\
\hline دالة & 0.00 & 6.898 & 9.328 & 24.090 & 10.503 & 33.78 & لبإِعلان التأثز التلبفزبيوني \\
\hline
\end{tabular}

من الجدول السابق رقم (†) يتضح ما يلي: لقد أظهرت النتائج وجود فروق في بُعد في

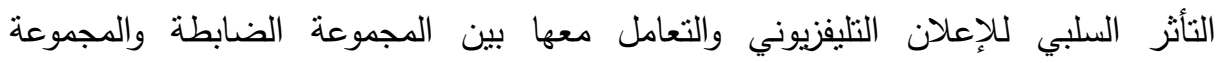
التجريبية، بعد نطبيق البرنامج لصالح المجموعة التجريبية، حيث كان متوسط المجموعة

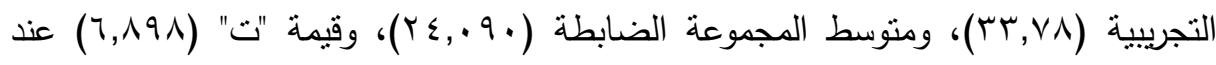
مستوي معنوية (0., •)، وهي بذلك تكون دالة إحصائيًا، ومن هنا نستطيع القول بأنه توجد

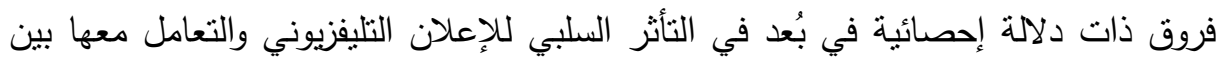
المجموعة الضابطة والمجموعة التجريبية، بعد تطبيق البرنامج لصالح المجموعة التجريبية.

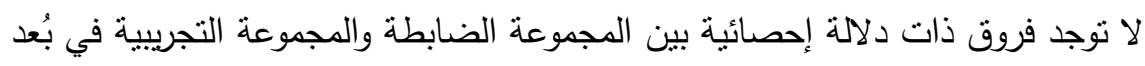

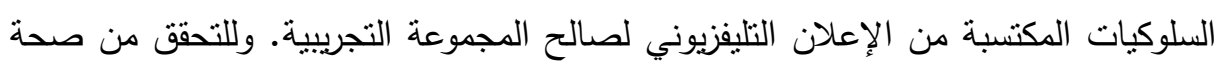
هذا الفرض قامت الباحثة باستخدام اختبار Independent Samples Test لعينتين من الاعني مستقلتين، لتعرف على دلالة الفروق بين المجموعة الضابطة والمجموعة التجريبية. 
جدول رقم(V): يوضح الفروق بين المجموعة التجريبية والمجموعة الضابطة في بُعد السلوكيات المكتسبة من الإعلان التليفزيوني بعد تطبيق البرنامج باستخدام

اختبار "ت" لعينتين مستقلتين (Independent t test)

\begin{tabular}{|c|c|c|c|c|c|c|c|}
\hline \multirow{2}{*}{ النتيجة } & \multirow{2}{*}{ الدلالةي } & \multirow[b]{2}{*}{ 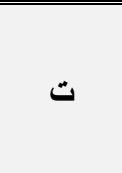 } & \multicolumn{2}{|c|}{ المجموعة الضابطة } & \multicolumn{2}{|c|}{ التجريبية } & \multirow[b]{2}{*}{ المقياس } \\
\hline & & & انحرافي & متوسط & انحراف & مستوسط & \\
\hline دالة & 0.00 & 10.209 & 7.104 & 21.180 & 8.905 & 32.81 & 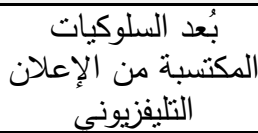 \\
\hline
\end{tabular}

من الجدول السابق رقم (V) يتضح ما يلي: لقد أظهرت النتائج وجود فروق في بُعد في السلوكيات المكتسبة من الإعلان التليفزيوني بين المجموعة الضابطة والمجموعة التجريبية، بعد تطبيق البرنامج لصالح المجموعة التجريبية، حيث كان متوسط المجموعة التجريبية (Y,^)

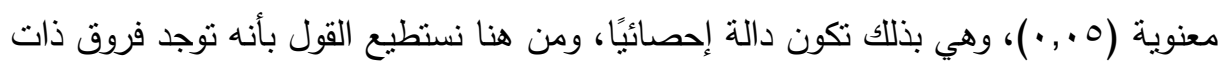
دلالة إحصائية في بُعد السلوكيات المكتسبة من الإعلان التليفزيوني بين المجموعة الضابطة والمجموعة التجريبية، بعد تطبيق البرنامج لصالح المجموعة التجريبية. لا توجد فروق ذات دلالة إحصائية بين المجموعة الضابطة والمجموعة التجريبية في بُعد لبعديج

البرامج التجارية للإعلان التليفزيوني عند الأطفال لصالح المجموعة التجريبية. Independent للتحقق من صحة هذا الفرض قامت الباحثة باستخدام اختبار Samples Test والمجموعة التجريبية. 
جدول رقم(^): يوضح الفروق بين المجموعة التجريبية والمجموعة الضابطة في بُعد البرامج التجارية للإعلان التليفزيوني عند الأطفال بعد تطبيق البرنامج باستخدام

اختبار "ت" لعينتين مستقلتين (Independent t test)

\begin{tabular}{|c|c|c|c|c|c|c|c|}
\hline \multirow[b]{2}{*}{ النتيجة } & \multirow[b]{2}{*}{ مستولة } & \multirow[b]{2}{*}{ ت } & \multicolumn{2}{|c|}{ المجموعة الضابطة } & \multicolumn{2}{|c|}{ المجموعة التجريبية } & \multirow[b]{2}{*}{ المقياس } \\
\hline & & & معياري & متوسبى & معياري & متوسط & \\
\hline دالة & 0.00 & 6.762 & 7.332 & 22.130 & 10.119 & 30.580 & لبُعد البرامجن التنليفزيوني التجارية \\
\hline
\end{tabular}

من الجدول السابق رقم (^) يتضح ما يلي: لقد أظهرت النتائج وجود فروق في بُعد في البرامج التجارية للإعلان التليفزيوني عند الأطفال بين المجموعة الضابطة والمجموعة التجريبية، بعد تطبيق البرنامج لصالح المجموعة التجريبية، حيث كان متوسط المجموعة

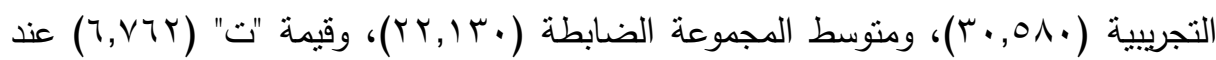
مستوي معنوية (0., •)، وهي بذلك تكون دالة إحصائيًا، ومن هنا نستطيع القول بأنه نوجد

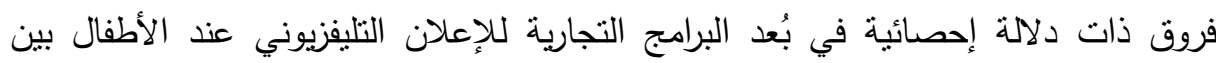
المجموعة الضابطة والمجموعة التجريبية، بعد تطبيق البرنامج لصالح المجموعة التجريبية. توجد فروق ذات دلالة إحصائية بين منوسط درجات المجموعة التجريبية في القياس

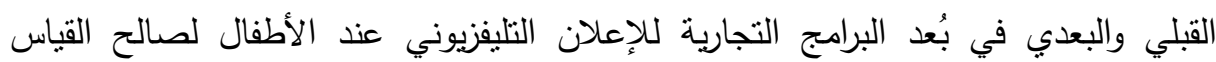

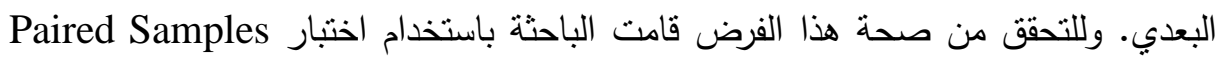
لعينتين مرتبطنين، لتعرف على دلالة الفروق بين الاختبار القبلي والبعدي للمجموعة التجريبية. جدول رقم(9): يوضح الفروق بين - القياس القبلي والبعدي- للمجموعة التجريبية بُعد البرامج التجارية

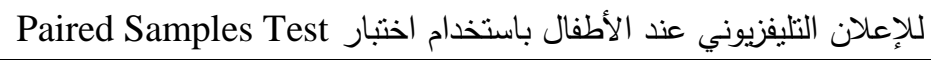

\begin{tabular}{|c|c|c|c|c|c|c|c|}
\hline \multirow{3}{*}{ النتيجة } & \multirow{3}{*}{ الدلالة } & \multirow{3}{*}{ ت ت } & \multicolumn{4}{|c|}{ المجموعة التجريبية } & \multirow{3}{*}{ المقياس } \\
\hline & & & \multicolumn{2}{|c|}{ القياس البعدي } & \multicolumn{2}{|c|}{ القياس القبلي } & \\
\hline & & & انحراف & متوسط & معياري & متوبطي & \\
\hline دالة & $\cdot, \cdots$ & $\vee, \Sigma \wedge q$ & 1. ro. & ए, $\leqslant 0$. & $7, \varepsilon \wedge \varepsilon$ & YY,9T & لبلعد البرامج التجارية التليفزيوني \\
\hline
\end{tabular}


من الجدول السابق رقم (9) ينضح ما يلي: لقد أظهرت النتائج وجود فروق بين منوسط درجات المجموعة التجريبية في القياس القبلي والبعدي في بُعد البرامج التجارية للإعلان

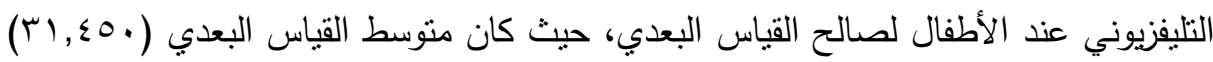

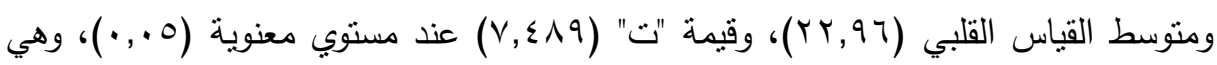
بذلك تكون دالة إحصائًًا، ومن هنا نستطيع القول بأنه توجد فروق ذات دلالة إحصائية بين

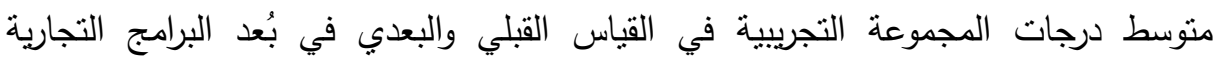
للإِعلان التليفزيوني عند الأطفال لصالح القياس البعدي. توجد فروق ذات دلالة إحصائية بين متوسط درجات المجموعة التجريبية في القياس القبلي والبعدي في بُعد النتوير التعليمبة للإعلان التليفزيوني عند الأطفال لصالح القياس

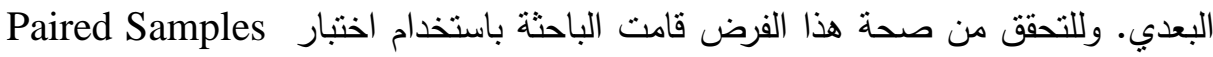
لعينتين مرتبطنين، لتعرف على دلالة الفروق بين الاختبار القبلي والبعدي للمجموعة

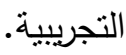
جدول رقم(• (1): يوضح الفروق بين - القياس القبلي والبعدي- للمجموعة التجريبية بُعد التتوير التعليمية للإعلان التليفزيوني عند الأطفال باستخدام اختبار

Paired Samples Test

\begin{tabular}{|c|c|c|c|c|c|c|c|}
\hline \multirow{3}{*}{ النتيجة } & \multirow{3}{*}{ مستوي } & \multirow{3}{*}{ ت } & \multicolumn{4}{|c|}{ المجموعة التجريبية } & \multirow{3}{*}{ المقياس } \\
\hline & & & \multicolumn{2}{|c|}{ القياس البعدي } & \multicolumn{2}{|c|}{ القياس القبلى } & \\
\hline & & & انحراف & متابي & معياري & متابي & \\
\hline دالة ل & $\cdot, \cdots$ & 7,179 & IT,IVT & $r q, \leqslant 0$. & $\vee, \vee \neg V$ & YI, V. & لبعد التتوبر التعليمية \\
\hline
\end{tabular}

من الجدول السابق رقم (• (1) يتضح ما يلي: لقد أظهرت النتائج وجود فروق بين متوسط درجات المجموعة التجريبية في القياس القبلي والبعدي في بُعد النتوير التعليمبة للإعلان

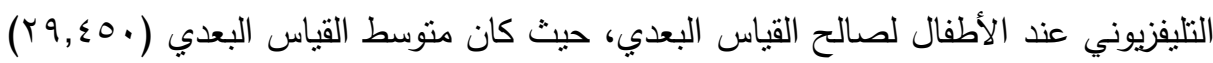

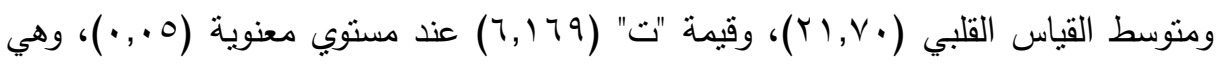
بذلك تكون دالة إحصائيًا، ومن هنا نستطيع القول بأنه نوجد فروق ذات دلالة إحصائية بين

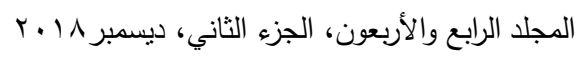


متوسط درجات المجموعة التجريبية في القياس القبلي والبعدي في بُعد التتوير التعليمية للإعلان التليفزيوني عند الأطفال لصالح القياس البعدي.

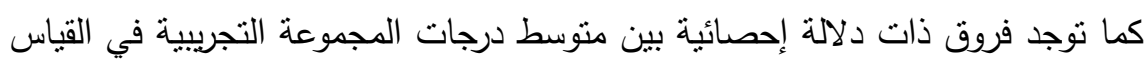

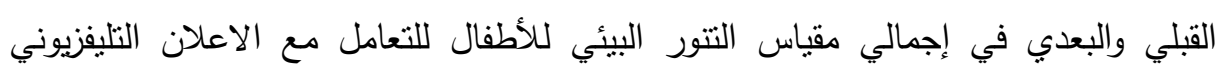
لصالح القياس البعدي. وللتحقق من صحة هذا الفرض قامت الباحثة باستخدام اختبار Paired Samples Test

$$
\text { والبعدي للمجموعة التجريبية. }
$$

جدول رقم(1): يوضح الفروق بين - القياس القبلي والبعدي- للمجموعة التجريبية بُعد التتوير التعليمية للإعلان التليفزيوني عند الأطفال باستخدام اختبار

Paired Samples Test

\begin{tabular}{|c|c|c|c|c|c|c|c|}
\hline \multirow{3}{*}{ التتيجة } & \multirow{3}{*}{ الالالة } & \multirow{3}{*}{ ت } & \multicolumn{4}{|c|}{ المجموعة التجريية } & \multirow{3}{*}{ المقياس } \\
\hline & & & \multicolumn{2}{|c|}{ القياس البعدي } & \multicolumn{2}{|c|}{ القياس القبلي } & \\
\hline & & & معياري & متوبط & معياري & متسابي & \\
\hline دالة ل & $\cdot, \cdots$ & Ar,I & rV, 701 & I & $1 V, r \mid q$ & $\mid \cdot T, Y 1$ & 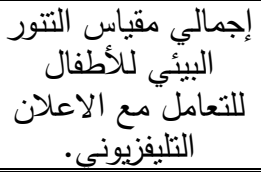 \\
\hline
\end{tabular}

من الجدول السابق رقم (11) يتضح ما يلي: لقد أظهرت النتائج وجود فروق بين منوسط درجات المجموعة التجريبية في القياس القبلي والبعدي في إجمالي مقياس التتور البيئي للأطفال للتعامل مع الاعلان التليفزيوني لصالح القياس البعدي، حيث كان متوسط التيدي القياس

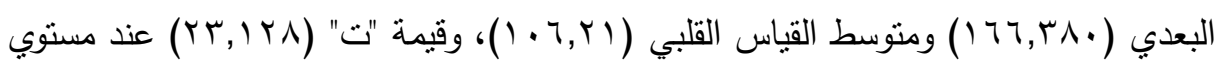

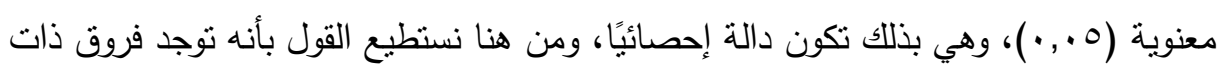
دلالة إحصائية بين منوسط درجات المجموعة التجريبية في القياس القبلي والبعدي في إجمالي لئي

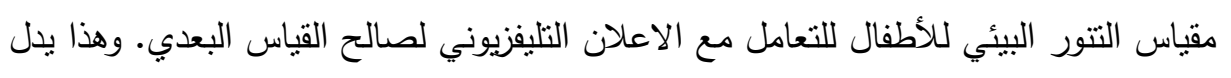

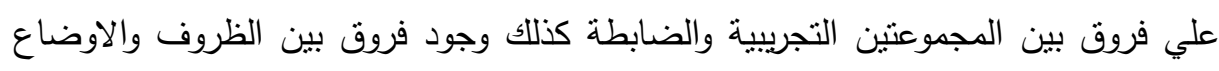
التى يعيشونها. 


\section{تروسياهي التصواسمة}

هادة النظر في الجدول المدرسي اليومي بحيث يسمح بممارسة الأنشطة المدرسية

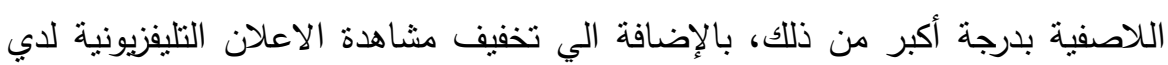

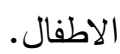

إعداد مشرفين ومشرفات مدربين ومتخصصين في نطوير وتتفيذ الأنشطة اللاصفية وإعداد

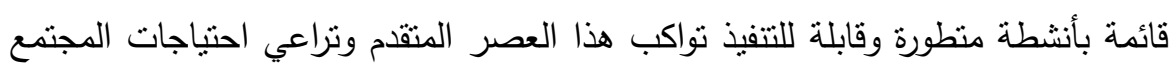
المدرسي وذلك لجميع المراحل التعليمية وخاصة الاساسية. هوفير الإمكانيات المادية من أماكن وأدوات واموال للإسهام في رفع درجة ممارسة الانشية النشة المدرسية بصورها المختلفة. ينبغي عمل نتوير للأسرة والمدرسة في التعامل مع الاعلان التليفزيوني المرتبط ببعض العادات السلوكية. عمل برنامج نزبوي علاج للحد من التأثر السلبي للإعلان التليفزيوني والتعامل معها. عمل منشورات في المدرسة عن السلوكيات المكتسبة من الإعلان التليفزيوني. نشر في الجهات التعليمة والتربوية واعلامية مجلات التنوير التعليمية للإعلان التليفزيوني الإني

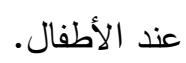

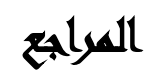

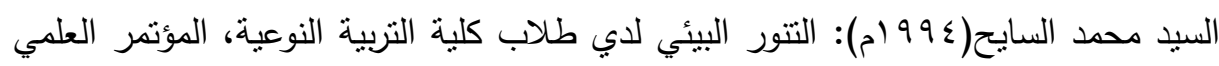

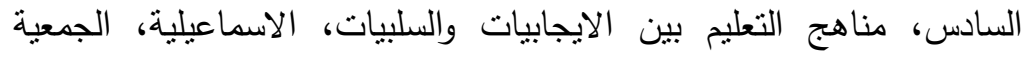
المصرية للمناهج وطرق التدريس.

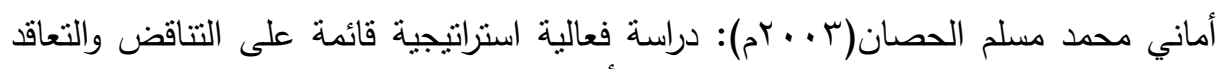

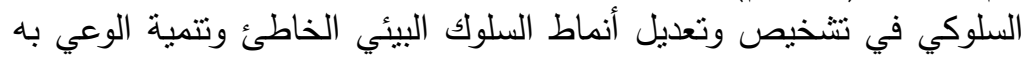

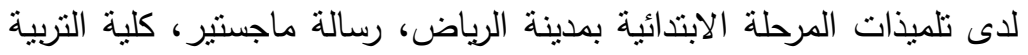

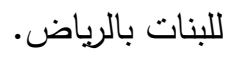


جاسم صالح عبد الله: التتور البيئي لاى معلمي العلوم بالمرحلة المنوسطة بدولة الكويت،

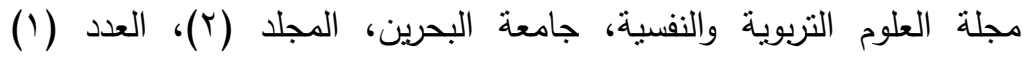

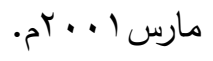

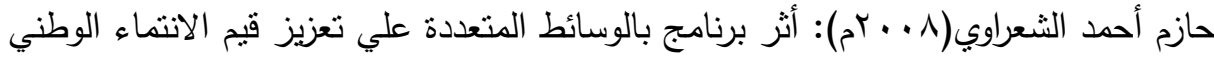

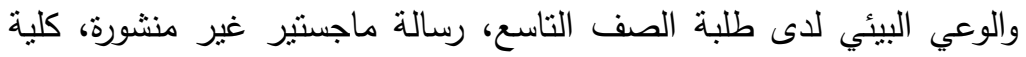

$$
\text { التربية الجامعة الإسلامية بغزة. }
$$

حامد عبد السلام زهران( •99 (م)): علم نفس النمو "الطفولة والمراهقة"، عالم الكتب، القاهرة،

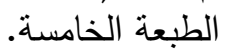

حسن الكناني(1 ( • r م): الإعلام الفضائي والجنس، عمان، الأردن، دار أسامة لنشر والتوزيع.

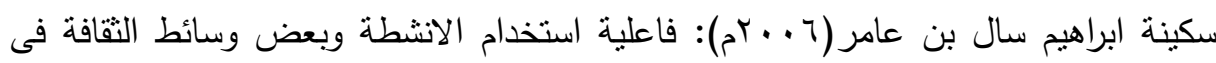

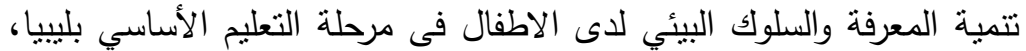
رسالة دكتوراه، معهز الدراسات والبحوث البيئية جامعة عين شمس.

سيد محمدين( 0. . rم).: حقوق الإنسان بين النظرية والنطبيق فى مجال استراتيجيات حماية

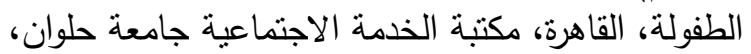

عطا درويش وتيسير محمود نشوان: اثر مقرر التربية البيئية على مستوى التتور البيئى لطلاب

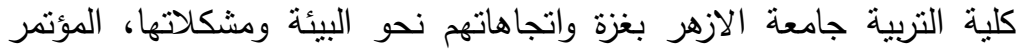

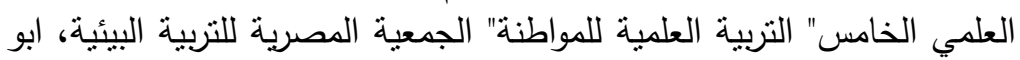

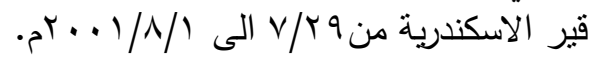

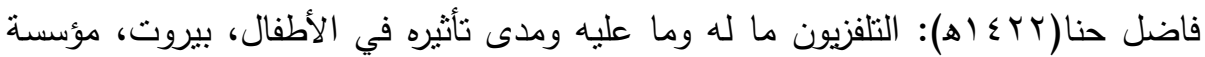

$$
\text { الرسالة. }
$$

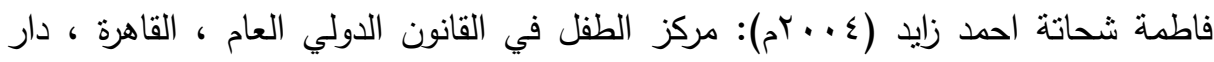

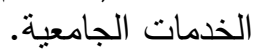

فايز محمد عبده وأبو السعود محمد أحمد(ب99 (م)): مدي اكتساب عناصر التتور البيئي لدي

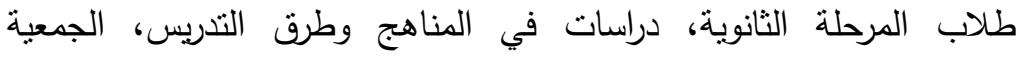
المصرية للمناهج وطرق التدريس.

فتحي مصطفي الزيات(797 (1) : سيكولوجية التعلم، دار النشر للجامعات، الطبعة الأولي.

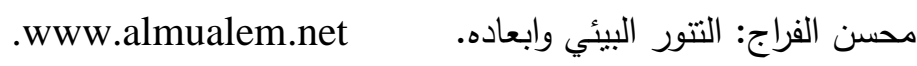
محمد شحاته ربيع(T/91 ام ): تاريخ علم النفس ومدارسه، دار الصحوة. 
مجلة العلوم البيئية

معهد الدراسات والبحوث البيئة - جامعة عين شمس

محمد مرتضي الزبيدي: تاج العروس من جواهر القاموس، بيروت، دار مكتبة الحياة، ب ت.

Vlaardingerbroek, B. \& Taylor, T., " The environmental knowledge and attiudes of prospective teachers in Lebanon: A Comparative study. International Research in Geographical and Environmental Education,2007, 16 (2), pp120-134.

\title{
APROPOSED PROGRAM FOR CHILDREN \\ ENVIRONMENTAL LITERACY FOR DEALING \\ WITH TELEVISION ADVERTISMENT ASSOCIATED \\ WITH SOME BEHAVIORAL HABITS
}

[14]

\author{
Amal, S. Abd El Hamid ${ }^{(1)}$; Laila, A. A. Karam El-din ${ }^{(2)}$ \\ and Omnia, A. Ali ${ }^{(1)}$ \\ 1) Institute of Environmental Studies and Research, Ain Shams \\ University. 2) Faculty of Postgraduate Childhood Studies, Ain Shams \\ University
}

\begin{abstract}
The current study's purpose is to determine the environmental literacy level among children before suggesting application of a proposed program for environmental literacy through using commercials and different television programs. The study also aims at developing children' environmental literacy in order to restrict children' improper habits through applying the suggested program for environmental literacy that uses commercials and different television programs. The study uses the experimental method, counting on scale of environmental literacy for children for dealing with television advertisements involved in some behaviors and habits of the study sample items. The study Sample consists of (100) male/female students divided as follows: 25 females and 25 males from Taibah International

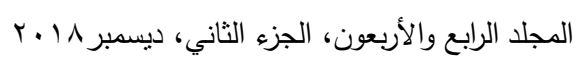


Language School, 25 females and 25 males from the King Fahd Official Language Schools Complex experimental group). Control group: (100) students divided as follows: 25 females and 25 males from Taibah International School for Languages, 25 females and 25 males from the King Fahd Academic Complex of Languages. Study data are obtained from the subjects follows the natural distribution. The test results indicate that the probable value for each dimension is greater than 0.05 , indicating that the data are following the natural trace of distribution and that laboratory tests must be used. Results of testing the study hypotheses show that there are statistically significant differences regarding the dimension of using TV advertisement between the control group and the experimental group after dealing with the TV advertisement that is associated with some behavioral habits, in favor of the experimental group, registering (31.40) while the control group has registered (21.46) and $\mathrm{T}$ value is (7.403) at (0.05) significance level asserting being statistically significant. Hence, we can say that there are statistically significant differences in the dimension of dealing with the TV advertising associated with some behavioral habits between the control group and the experimental group after applying the program to the experimental group, in favor of the experimental group. The researchers recommend applying the program of environmental literacy for children to deal with television advertising associated with some behavioral habits. 